\title{
UM MONSTRO CHAMADO SOCIEDADE: DO GÓTICO POLÍTICO À DISTOPIA
}

\section{A MONSTER CALLED SOCIETY: FROM THE POLITICAL GOTHIC TO THE DYSTOPIA}

\author{
Pedro Sasse ${ }^{1}$
}

\begin{abstract}
RESUMO: O gótico é indissociável do contexto político em que surge, e permanece, ao longo de sua trajetória, em diálogo com questões relacionadas a poder, controle $e$ transgressão. Não obstante, há momentos em que comentários sociopolíticos assumem protagonismo e os mecanismos do gótico ganham fins retóricos para além da narrativa em si. William Godwin, Charles Dickens e George Reynolds são autores pioneiros nesse uso do gótico, em que Fred Botting ressalta a construção de um Estado monstruoso e os horrores da opressão criada por uma justiça corrupta, e que David Punter chamará de "Political Gothic". Apresenta-se, aqui, a hipótese de que os temas e estratégias presentes nesse uso do gótico se aplicariam também a outro gênero profundamente engajado com seu contexto político-social, a distopia. Buscamos, assim, apresentar como a ficção distópica dá continuidade a essa tradição de representações monstruosas da sociedade a partir da obra de Jack London.
\end{abstract}

PALAVRAS-CHAVE: gótico; distopia; cidade; monstro; sociedade

\begin{abstract}
The gothic is inseparable from the political context in which it emerges, and remains, throughout its trajectory, in dialogue with issues related to power, control and transgression. However, there are occasions in which sociopolitical commentaries take center stage, and the rhetorical mechanisms of the gothic reach towards ends beyond the narrative itself. William Godwin, Charles Dickens e George Reynolds are forerunners in this use of the gothic, in which Fred Botting highlights the construction of a monstrous state and the horrors of the oppression created by a corrupt justice system, and which David Punter will name "Political Gothic". We present here the hypothesis that the themes and strategies present in this use of the gothic could also be applied to another genre profoundly engaged with its own sociopolitical context, the Dystopia. Thus, we seek to show how dystopian fiction continues this tradition of monstrous representations of society.
\end{abstract}

KEYWORDS: gothic; dystopia; city; monster; society

William Godwin escolhe o dia 12 de maio de 1794 para a publicação de Calleb Williams, mesmo dia em que o primeiro ministro britânico inicia uma onda de prisões aos

\footnotetext{
${ }^{1}$ Doutor em Estudos de Literatura pela UFF e Pós-Doutorado na UFF.
} 
suspeitos de envolvimento com movimentos radicais influenciados pelos revolucionários franceses. Na França, vive-se o chamado Período do Terror, marcado pela execução de milhares de pessoas durante a revolução francesa. É, também, um período de terror para a literatura, marcando a década de apogeu da literatura gótica, e Sade é preciso ao apontar a relação entre ambos os eventos em "A arte de escrever ao gosto do público", em que considera o gótico como "o fruto indispensável dos abalos revolucionários de que a Europa inteira se ressentia" (SADE, 2002, p. 45).

O prefácio escrito por Godwin para sua publicação acaba extirpado da obra por seus editores, temerosos que tal texto fosse tomado como prova de contato com os radicais. No pequeno texto, o autor apresenta menos a obra em si que sua proposta geral: a de que o sistema político tem uma influência direta sobre a moral do povo que vive sob seu domínio, que "o espírito e o caráter do Governo penetra em cada camada da sociedade"2 (GODWIN, 1831, p. 19. Tradução nossa). Dessa forma, pretende apresentar "uma revisão geral dos modos de um despotismo doméstico e sem registros pelo qual o homem se torna o destruidor do próprio homem"3 (p. 19).

Botting situa a obra de Godwin como um momento de virada do gótico em que a estrutura inaugurada por Otranto começa a dar lugar a um gótico mais interiorizado - mas ao mesmo tempo mais pungente em sua crítica sociopolítica. Segundo o autor:

\begin{abstract}
Mecanismos e personagens do gótico antigo, usados excessivamente ao ponto do cliché, são transformados em sinais de tirania aristocrática, sobras de um mundo não esclarecido. O vilão perturbador e demoníaco, no entanto, retém um atrativo sombrio, embora ambivalente, fascina como um rebelde desafiador dos entraves dos costumes sociais. A simpatia por indivíduos condenados, em sofrimento, encontra expressão na identificação romântica com Prometeu e o Satã de Milton, considerados heróis pela sua resistência para derrocar a tirania. $\mathrm{O}$ vilão ou proscrito, diferente de diversos textos radcliffeanos, não é a causa do mal e do terror, um objeto para ser execrado a fim de que a ordem seja restaurada. É uma posição que pede compreensão e respeito. O mal real é identificado entre corporificações de tirania, corrupção e preconceito, identificado entre certas figuras, frequentemente aristocráticas, e, ainda com mais frequência, com instituições de poder manifestadas em hierarquias de governo, normas sociais e superstição religiosa. ${ }^{4}$ (BOTTING, 2005, p. 60. Tradução nossa)
\end{abstract}

2 "the spirit and the character of the government intrudes itself into every rank of society".

3 "a general review of the modes of domestic and unrecorded despotism by which man becomes the destroyer of man".

4 "Older Gothic figures and devices, overused to the point of cliché, are transformed into signs of aristocratic tyranny, leftovers from an unenlightened world. The disturbing and demonic villain, however, retains a darkly attractive, if ambivalent, allure as a defiant rebel against the constraints of social mores. The sympathies for suffering, doomed individuals find expression in Romantic identifications with Prometheus and Milton's Satan, regarded as heroes because of their resistance to overpowering tyranny. The villain or outcast, unlike much Radcliffean writing, is not the cause of evil and terror, an object to be execrated so that order can be restored. It is a position which calls for respect and understanding. Real evil is identified among embodiments of tyranny, corruption and prejudice, identified with certain, often aristocratic, figures and, more frequently, with institutions of power manifested in government hierarchies, social norms and religious superstition". 
Se olharmos já para as primeiras frases de Caleb Williams, veremos sintetizada essa atmosfera de confronto entre um sistema social tirânico e um indivíduo que é alienado por esse sistema:

\begin{abstract}
Minha vida tem sido, por vários anos, um teatro de calamidades. Eu fui marcado pela vigilância da tirania, e não pude escapar. Minhas esperanças mais razoáveis foram destruídas. Meu inimigo se mostrou indiferente a súplicas e incansável na perseguição. Minha fama, assim como minha felicidade, se tornou a vítima. Todos, até onde minha história é conhecida, se negaram a auxiliar-me no meu sofrimento, e execraram meu nome. ${ }^{5}$ (GODWIN, 1831, p. 21. Tradução nossa)
\end{abstract}

Em obras como a de Godwin, em que o gótico se inclina mais profundamente para a preocupação da crítica sociopolítica - não de forma metafórica, como, seria possível alegar, o gótico como um todo faz, mas tomando o próprio sistema sociopolítico como monstruosidade central da obra -, vemos surgir os claros contornos de um outro gênero que só se consolidaria mais de cem anos depois, a ficção distópica.

De fato, poderíamos tomar as palavras introdutórias de Caleb no romance de Godwin como uma fala de Winston Smith sem maiores mudanças: um indivíduo se vê marcado por um sistema tirânico, tenta, mas não consegue escapar, e tem suas esperanças destruídas por um inimigo inalcançável e incansável enquanto todos a sua volta não só negam qualquer tipo de auxílio como execram seu nome.

Não queremos, com isso, de forma alguma caracterizar Caleb Williams como uma protodistopia, mas, pelo contrário, mostrar como a tradição orwelliana pode ser lida como uma variação de uma vertente do gótico comprometida com uma crítica sociopolítica de seu contexto de produção através de uma representação monstruosa de determinados aspectos da sociedade, geralmente envolvendo miséria, degeneração social, paranoia, vigilância e perseguição, entre outros.

Em visões mais abrangentes do conceito de distopia enquanto gênero literário, vemos, muitas vezes, serem incluídas em seu escopo obras que, diferente das distopias clássicas Nós, 1984, Admirável mundo novo etc. - dispensam a ambientação futurista ou mesmo a representação de uma sociedade organizada distinta da nossa. Assim, através dessas conceituações mais flexíveis, obras como $O$ senhor das moscas, de William Golding, ou $O$ processo, de Franz Kafka, são classificadas como distopias pelas mesmas características que poderíamos indicar como próprias para definir as obras do próprio gótico político.

5 "My life has for several years been a theatre of calamity. I have been a mark for vigilance of tyranny, and I could not escape. My fairest prospects have been blasted. My enemy has shown himself inaccessible to entreaties, and untired in persecution. My fame, as well as my happiness, has become the victim. Every one, as far as my story has been know, has refused to assist me in my distress, and has execrated my name". 
Se abandonarmos uma visão mais estreita da ficção distópica e dispensarmos, por exemplo, a ambientação futurista como uma especificidade do gênero, veremos as fronteiras entre essas obras situadas no presente e consideradas, muitas vezes, distopias - como o Senhor das Moscas, de William Golding, ou O processo, de Franz Kafka - e os romances góticos centrados na crítica política se dissolverem ao ponto de se tornarem sinônimos.

David Punter (2013, p. 118), em The Literature of Terror, chamará Caleb Williams de "gótico político", pouco depois de associar seu autor com autores como Kafka e Dostoievsky no que diz respeito à construção de "mundos de pesadelo". Punter ressalta como Godwin aloca sua escrita ficcional dentro de um projeto mais amplo, predominantemente intelectual, filosófico e político, afirmação que poderia ser estendida, de forma geral, à escrita da ficção distópica.

Tomando como raiz da ficção distópica a tradição utópica com que dialoga, vemos surgir de forma muito clara esse projeto político-filosófico mais amplo: como categorizar uma obra como Utopia (1516), de More, ou Nova Atlântida (1627), de Bacon? Ficção? Ensaio filosófico? Experiência de pensamento? Crítica política alegórica? Especulação sociológica? Se o romance distópico, por sua vez, firmou de forma mais clara seus fundamentos na fícção, não podemos dizer, no entanto, que tenha abandonado essa forte proximidade com um projeto político-filosófico, dada a clara carga alegórica que relaciona os mundos imaginados ao contexto de produção dessas obras.

Diferente de seus antecessores utópicos, no entanto, os romances distópicos parecem expandir suas ferramentas retóricas para além da experiência de pensamento racional que vemos em Utopia, por exemplo. Da mesma forma que a guinada romântica do gótico, ao mesmo tempo, interioriza os horrores e intensifica a crítica política, representando personagens rebeldes, alienados pelo sistema, sofrendo os horrores da tirania ou da corrupção de suas sociedades, como ressalta Botting, a virada distópica parece seguir uma trajetória semelhante: o peso que antes recaía quase exclusivamente sobre a descrição do espaço e de seu funcionamento, em que o protagonista serve com mera testemunha maravilhada desse espaço outro, agora recai sobre um protagonista alienado desse - ou por esse - próprio sistema, e o espaço passa a ser filtrado pela visão de um personagem que sofre seus horrores.

Dessa forma, o que antes era majoritariamente um discurso apoiado na demonstração lógica para construção de um argumento utópico, na distopia, fará também um apelo emocional. É nesse ponto em que as ferramentas do gótico entram em jogo: expondo o leitor aos efeitos estéticos de horror construídos a partir da exposição da situação terrífica em que se 
encontra um personagem, busca-se que o leitor associe esses sentimentos negativos à situação sociopolítica que se busca criticar.

Apresenta-se aqui, então, a hipótese de que a ficção distópica se alinha a essa intercessão entre o gótico e a ficção política, em que os efeitos estéticos produzidos pelos mecanismos góticos servem de suporte a um propósito filosófico, político e intelectual maior, interseção que denominaremos, seguindo a etiqueta de Punter, de gótico político. Buscaremos, assim, traçar um breve panorama que uniria Caleb Williams às distopias do século XX enquanto representações góticas de sistemas sociopolíticos, assim como esboçar algumas características que ressaltam de que forma o gótico é utilizado como ferramenta retórica por essas obras.

Sendo a distopia, neste trabalho, menos nosso eixo que nosso ponto de chegada, optaremos por levar nossa trajetória até uma obra do gênero anterior aos grandes clássicos inaugurais do gênero - Nós (1924), de Yevgeny Zamyatin, Admirável mundo novo (1932), de Aldous Huxley e 1984 (1949), de George Orwell: a precursora distopia anticapitalista O tacão de ferro (1908), de Jack London. Com isso, nos centramos mais em um panorama que una o gótico tradicional à distopia por meio desse uso político de seus mecanismos, deixando para uma análise futura um aprofundamento nas variadas aplicações que serão encontradas dentro do gênero distópico lato sensu (as distopias totalitárias, as distopias do consumo, a ficção pósapocalíptica etc.).

\section{Uma ferramenta retórica}

Um aspecto crucial para o gótico é a construção do espaço. No exercício de tentar identificar que aspectos podem unir a complexa heterogeneidade daquilo se chama até hoje por gótico - tarefa quase sempre ingrata -, Jerrold Hogle o escolhe como primeira característica a ser elencada:

\footnotetext{
Uma história Gótica geralmente tem lugar (ao menos parcialmente) em um espaço antiquado ou aparentemente antiquado - seja ele um castelo, um palácio estrangeiro, uma abadia, uma vasta prisão, uma cripta subterrânea, um cemitério, uma fronteira ou ilha primitiva, um velho casarão ou teatro, uma cidade antiga ou o submundo urbano, um armazém decadente, fábrica, laboratório, prédio público, ou algum tipo de recriação de um local antigo, como um escritório com velhos armários de arquivo, uma nave espacial desgastada, ou a memória de um computador ${ }^{6}$ (HOGLE, 2002, p. 2. Tradução nossa).
}

6 "a Gothic tale usually takes place (at least some of the time) in an antiquated or seemingly antiquated space be it a castle, a foreign palace, an abbey, a vast prison, a subterranean crypt, a graveyard, a primeval frontier or island, a large old house or theatre, an aging city or urban underworld, a decaying storehouse, factory, 
Esse espaço, no entanto, já é caracterizado por um elemento pertencente à dimensão temporal - "antiquado" - fazendo com que o tempo seja indissociável de sua constituição e, assim, elemento também fundamental da narrativa gótica:

Dentro desse espaço, ou combinação desses espaços, estão alguns segredos ocultos do passado (às vezes do passado recente) que assombram os personagens, psicologicamente, fisicamente, ou de outra forma no tempo principal da história ${ }^{7}$ (HOGLE, 2002, p. 2. Tradução nossa).

Por último, Hogle ressalta a manifestação corpórea desse espaço-tempo:

\begin{abstract}
Essas assombrações podem tomar distintas formas, mas geralmente assumem as feições dos fantasmas, espectros e monstros (misturando traços de diferentes reinos do ser, frequentemente vida e morte) que se erguem de dentro desse espaço antiquado, ou, em alguns casos, o invadem a partir de domínios do além, para manifestar crimes não resolvidos ou conflitos que não podem mais ser ocultados com $\operatorname{sucesso}^{8}$ (2002, p. 2. Tradução nossa).
\end{abstract}

Tomamos, assim, entre outros aspectos de suma importância para a caracterização do gótico - como o par transgressão e excesso aventado por Botting -, a tríade espaço, tempo e manifestação desse espaço-tempo - ou, nas palavras de Júlio França, locus horribilis, presença fantasmagórica do passado e personagem monstruosa (cf. FRANÇA, 2017, p. 24-25) - como elementos centrais para esse tipo de narrativa.

Se tais elementos já são naturalmente interligados e interdependentes, no gótico político veremos esses três elementos se fundirem por completo: a figura monstruosa, por mais que possa ter manifestações momentâneas, só existe de forma integral no fenômeno/sistema sociopolítico a ser criticado - desigualdade, capitalismo, fascismo, escravidão, anarquia; despersonificada, seu espaço é a parte visível de seu corpo monstruoso - a cidade decadente, o submundo violento, as cortes corruptas, as ruas vigiadas e controladas - e o segredo oculto, sua assombração, é justamente a exposição de suas mazelas - a miséria, a desigualdade, a tortura, a escravidão etc.

O prefácio de Caleb Williams já sintetiza essa amálgama ao apresentar a tese de que o espírito e o caráter do governo se infiltram em cada camada da sociedade, tornando tanto o espaço quanto seus habitantes um reflexo desse sistema maior. Aqueles personagens que

laboratory, public building, or some new recreation of an older venue, such as an office with old filing cabinets, an overworked spaceship, or a computer memory".

7 "Within this space, or a combination of such spaces, are hidden some secrets from the past (sometimes the recent past) that haunt the characters, psychologically, physically, or otherwise at the main time of the story".

8 "These hauntings can take many forms, but they frequently assume the features of ghosts, specters, or monsters (mixing features from different realms of being, often life and death) that rise from within the antiquated space, or sometimes invade it from alien realms, to manifest unresolved crimes or conflicts that can no longer be successfully buried from view." 
resistem, se opõem ou ao menos são capazes de enxergar além desse sistema monstruoso serão alienados e perseguidos. Dessa forma, ainda que pudéssemos dar a Falkland o título de monstro, o personagem é vítima de uma mentalidade, um código de conduta, que transcende sua vontade e que, em alguma medida, o torna prisioneiro - o que fica explícito em sua decadência pela culpa ao fim do romance.

Retomando, agora, as considerações de Botting sobre o que seria o eixo característico da narrativa gótica, transgressão e excesso, vale ressaltar como esse gótico político reforça esteticamente essa caracterização monstruosa de um sistema/fenômeno sociopolítico através de uma descrição sobrecarregada, excessiva, que propositalmente deforma o seu objeto em prol da crítica. Tal deformação, no entanto, é de intensidade mais que de natureza. Busca-se, através de uma representação gótica desse sistema, intensificar suas discrepâncias, seus horrores e os sofrimentos experimentados pelos personagens expostos a eles.

Se, como nos expõem suas primeiras frases, a própria condição de Caleb de constante perseguição, injustiça, angústia e culpa já marcam essa narrativa do excesso, há alguns capítulos que tornam ainda mais explícito o uso dos tons góticos para ressaltar os horrores do sistema, como podemos ver no capítulo XI do segundo volume.

Preso injustamente, Caleb descobre pela primeira vez os horrores da vida penitenciária, trancado atrás de "portas massivas" e transportado por "passagens sombrias" até um espaço de "degradação e imundície" que "parece já estar em um estado de aprodrecimento e infecção". Curioso notar que, diferente do que vemos em narrativas menos engajadas politicamente, não são os prisioneiros a serem contaminados pela caracterização gótica do espaço, mas os agentes de poder, os carcereiros, cujas faces, vazias de qualquer sentimento ou piedade, fazem com o que Caleb desvie o olhar em "incontrolável repúdio" 9 (GODWIN, 1931b, p. 22. Tradução nossa).

Godwin não perde a oportunidade de trazer à discussão a revolução francesa. Nesses trechos, o conteúdo político perde explicitamente a roupagem narrativa para assumir o primeiro plano, em uma interpelação direta aos leituras:

\footnotetext{
“Graças a Deus”, exclama o inglês, "Não temos Bastilha! Graças a Deus, conosco, nenhum homem pode ser punido sem crime!" Ingênuo miserável. Essa é uma terra de liberdade, em que milhares definham em masmorras e grilhões? Vá, vá, tolo ignorante! E visite as cenas de nossas prisões! Testemunhe sua insalubridade, sua sujeira, a tirania de seus governantes, a miséria de seus condenados! Depois disso, mostre-me um homem cínico o suficiente para, triunfante, dizer, a Inglaterra não tem Bastilha! ${ }^{10}$ (p. 28. Tradução nossa)
}

9 "massy doors" / "gloomy passages" / "squalidness and filth" / "appears to be already in a state of putridity and infection" / "unconquerable loathing".

10 “'Thank God,' exclaims the Englishman, 'we have no Bastile! Thank God, with us no man can be punished without a crime!' Unthinking wretch! Is that a country of liberty, where thousands languish in dungeons and 
A conclusão da experiência de Caleb nas prisões é a transformação do locus horribilis carcerário em uma metonímia de uma sociedade monstruosa, em que todo progresso da modernidade parece ter culminado em um fracasso da própria razão humana: "Essa é a sociedade. Esse é o objeto, a distribuição da justiça, que é a finalidade da razão humana. Por isso os sábios labutaram, e as lamparinas queimam em vão. - Por isso!""11 (GODWIN, 1931b, p. 28. Tradução nossa).

Se, no século XVIII, o gótico político ainda ensaiava seus primeiros movimentos, a mudança de eixo do gótico no século XIX para o contexto urbano moderno consolidará esse uso nas críticas à metrópole industrial. Punter traça, em alguns momentos de The Literature of Terror, o que seria a trajetória de uma tradição centrada em uma "retórica da injustiça social", utilizada como "arma política em um contexto contemporâneo"12 (PUNTER, 2013, p. 155. Tradução nossa), tradição essa que começaria em Godwin e prosseguiria em nomes como Bulwer Lytton, William Harrison Ainsworth, G. W. M. Reynolds e Charles Dickens.

Se observarmos, por exemplo, a síntese da cidade industrial dickensiana, Coketown, de Tempos difíceis (1854), já encontraremos nela, em germe, esse espaço distópico de controle, mecanização e reificação do homem. Botting descreve Coketown como "um labirinto industrial inumano e lúgubre, a concretização de um racionalismo distorcido e redutivo que tem seu equivalente ideológico representado pela tirania dos números e fatos ${ }^{13}$ ", (BOTTING, 2005, p. 82. Tradução nossa).

Podemos confirmar a visão de Botting tanto da forma quanto do conteúdo desse espaço. Por um lado, a cidade em si já é descrita de forma monstruosa ao usar justamente elementos do mundo natural como metáforas para caracterizar os piores aspectos de um mundo marcado justamente pela ação destrutiva do homem sobre a natureza:

Era uma cidade de tijolos vermelhos, ou de tijolos que seriam vermelhos caso as cinzas e a fumaça permitissem; mas, no estado de coisas de então, era uma cidade de vermelhos e negros antinaturais, como o rosto pintado de um selvagem. Era uma cidade de máquinas e chaminés altas, pelas quais se arrastavam perenes e intermináveis serpentes de fumaça que nunca se desenrolavam de todo. Havia um canal negro e um rio que corria púrpura por causa da tintura malcheirosa, e grandes pilhas de edifícios cheios de janelas, onde se ouviam ruídos e tremores o dia inteiro, e onde o pistão das máquinas a vapor trabalhava monótono, para cima e para baixo,

fetters? Go, go, ignorant fool! and visit the scenes of our prisons! witness their unwholesomeness, their filth, the tyranny of their governors, the misery of their inmates! After that, show me the man shameless enough to triumph, and say, England has no Bastile!"

11 "This is the object, the distribution of justice, which is the end of human reason. For this sages have toiled, and midnight oil has been wasted. - This!"

12 "rethoric of social justice" / "political weapon in a contemporary context".

13 "a grimly inhuman industrial labyrinth, a realisation of a distorted and reductive rationalism that has its ideological equivalent represented by the tyranny of numbers and facts". 
como a cabeça de um elefante em estado de loucura melancólica. (DICKENS, 2014, p. 37)

Em seguida, Dickens mostra como esse locus horribilis concretiza em sua geografia os ideais monstruosos do pragmatismo industrial oitocentista, ao representar uma cidade completamente regida pela lógica desumanizada, cujo resultado se aproximará bastante do espaço distópico que veremos se consolidar no século XX:

\begin{abstract}
Não se via nada em Coketown que não fosse rigorosamente funcional. (...) Todos os letreiros públicos da cidade eram pintados da mesma maneira: letras severas em preto e branco. A prisão poderia ser a enfermaria, a enfermaria poderia ser a prisão, a sede da prefeitura poderia ser qualquer uma das duas, ou ambas, ou outra coisa qualquer, em que pesem as poucas diferenças estéticas de sua construção. Fatos, fatos, fatos, por todo o aspecto material da cidade; fatos, fatos, fatos por todo o imaterial também. (DICKENS, 2014, p. 37)
\end{abstract}

A união de nomes como Dickens e Reynolds não é vista apenas por Punter. À época, como o próprio crítico ressalta, já se viam semelhanças entre as obras de ambos, muitas das quais recaíam sobre essa visão sombria do corpo social. Se voltarmos a Mysteries of London (1845), encontraremos um forte uso do gótico para consolidar o que Punter chama de retórica da injustiça social. Os fins políticos, como vimos em Godwin, são explicitamente marcados no prefácio à obra, em que Reynolds faz um longo discurso sobre a desigualdade social, que será a força motriz do romance:

Entre essas cidades, há uma em que contrastes de uma estranha natureza existem. A mais irrestrita riqueza é vizinha da mais hedionda pobreza; a mais deslumbrante pompa é posta em forte relevo pela mais deplorável sordidez; o luxo mais sedutor está separado apenas por um estreito muro da mais chocante miséria ${ }^{14}$ (REYNOLDS, 2014, s.p. Tradução nossa)

Em Mysteries of London, a finalidade política é tão explícita que alguns capítulos, como "New Year's Day", dedicarão amplo espaço à reflexão social, contendo não apenas um discurso condenando a desigualdade, como gráficos e tabelas estatísticas indicando os números chocantes dessa disparidade. Para corresponder, no campo estético, essa crítica pungente à desigualdade social, Reynolds, como antes Dickens em Oliver Twist (1838), transforma os espaços de miséria da cidade em verdadeiros loci horribiles carregando-os de tons góticos pelo signo do excesso, seja o excesso de repugnância, de miséria ou de transgressões.

14 "Amongst these cities there is one in which contrasts of a strange nature exist. The most unbounded wealth is the neighbour of the most hideous poverty; the most gorgeous pomp is placed in strong relief by the most deplorable squalor; the most seducing luxury is only separated by a narrow wall from the most appalling misery". 
Nas ruas da cidade, descritas como "um labirinto de vielas, entulhadas de lixo, empesteadas por odores nauseantes, e infestada por uma população que nasce, vive e morre no meio da sordidez, da penúria, da miséria e do crime", vendedores de carcaças empesteiam a cidade com "um fétido e doentio odor, insuportável por qualquer estômago sensível". Nos estabelecimentos "ossos de animais são pendurados para descoloração, e agridem a vista tanto quanto o fedor horrível da carne causa repugnância aos nervos". Reynolds descreve como as moradias, longe de serem uma fuga para esse espaço repugnante, acabam, muitas vezes, em estado ainda pior. Nessas casas em dezenas de pessoas vivem pequenos cômodos, muitas vezes é necessário conviver por semanas com corpos de inquilinos recém mortos, a espera de um fim digno. Diante do calor e do confinamento, “[u]ma veloz decomposição ocorre - vida animal é gerada rapidamente; e em vinte e quatro horas miríades de abomináveis criaturas são vistas rastejando ali"15 (REYNOLDS, 2014, s.p. Tradução nossa).

Servindo de introdução ao capítulo denominado "Den of horrors", essas descrições sintetizam bem a visão que Reynolds, assim como outros autores de sua época, tenta passar dos bairros pobres da cidade. Ainda que pudéssemos trazer, a fim de demonstrar o uso dessa estética gótica, trechos em que os clichés espaciais do gênero são mais explícitos - como no capítulo dedicado a Newgate, por exemplo, descrito como um típico castelo gótico -, desejamos, com esta seleção, reforçar a caracterização monstruosa que permeia espaço, tempo e personagens: a cidade não só é repulsiva aos sentidos, mas também à moral, o que revela o atraso, a barbárie que persiste em meio à modernidade graças a esse sistema que perpetua e intensifica a desigualdade social. Vemos, ainda, como esse ambiente se apropria de um espaço típico do gótico, o labirinto, tornado agora ubíquo enquanto elemento característico da cidade de forma geral - característica, vale ressaltar, frequente no gótico oitocentista -, um labirinto que, além de desorientador, é ameaçador pela sua capacidade de degeneração das virtudes e pelo constante perigo do crime.

Ainda que, de fato, não seja necessário muito exagero para se alcançar uma descrição monstruosa dos bairros miseráveis da Londres industrial, propomos que o foco nas sensações, a constante menção aos elementos de degradação, pestilência e morte, a claustrofobia, a sobreposição de elementos conflitantes - vida e morte, humano e animal, família e sexo,

15 "a maze of narrow lanes, choked up with dirt, pestiferous with nauseous odours, and swarming with a population that is born, lives, and dies, amidst squalor, penury, wretchedness, and crime" / "a foetid and sickening odour which could not possibly be borne by a delicate stomach" / "bones of the animals are hung to bleach, and offend the eye as much as the horrible stench of the flesh acts repugnantly to the nerves" / "Rapid decomposition takes place - animal life generates quickly; and in four-and-twenty hours myriads of loathsome animalculæ are seen crawling about". 
miséria e luxúria - e a ameaça física e moral emanada por esse espaço constroem uma visão de mundo disfórica, propícia ao horror, e própria desse gótico político.

Esse uso do gótico, encontrado amplamente na literatura no século XIX, de fato se via tão eficaz como ferramenta retórica, capaz de convencer não apenas - ou não tanto - pela razão, mas também pelos efeitos estéticos causados no público, que mesmo fora da ficção propriamente dita, via-se essa caracterização da sociedade influenciada pelo gótico. Os jornais, assim como certos artigos e livros de cunho sociológico, apresentam os cenários da metrópole muitas vezes de forma indistinguível ao que encontraríamos na ficção gótica urbana, como vemos, por exemplo, em How the poor live (1889), de George Sims:

Mint e Borough apresentam cenas suficientemente horríveis para que, certamente, sejam dignos de um sério estudo; mas cena após cena é o mesmo. Trapos, terra, sujeira, miséria, as mesmas figuras, as mesmas faces, a mesma velha história de um quarto inabitável e ainda assim habitado por oito ou nove pessoas (...), a mesma negligência vergonhosa dos proprietários em todas as precauções sanitárias, pisos apodrecidos, paredes lodosas, janelas quebradas, escadarias sem sentido, telhados sem telha, e, ao redor da morada de centenas de cidadãos honestos, as abominações sem nome que só poderiam ser identificadas se estivéssemos contribuindo com [a revista científica] The Lancet em vez de escrevendo um livro ${ }^{16}$. (p. 45. Tradução nossa).

Longe de ser exclusividade do gótico inglês, esse uso político do gótico pode ser encontrado em obras que fogem à tradição mais restrita do gênero. Já se encontrava na referência de Reynolds, Os mistérios de Paris (1842), de Eugène Sue, cujo primeiro capítulo já marca bem a ambientação desse gótico urbano; mas também em obras da língua portuguesa, como no romance naturalista de Abel Botelho - sobretudo Amanhã (1901), em que os bairros operários são carregados de tons góticos - ou nos contos e crônicas decadentes de João do Rio, no Brasil ${ }^{17}$.

É também nessa disseminação do gótico político como ferramenta eficaz de crítica social que a distopia fará seus primeiros contatos com esse tipo de ficção, mesmo antes de pioneiros como Admirável mundo novo, de Aldous Huxley e 1984, de George Orwell.

\section{O gótico nas distopias}

16 "The Mint and the Borough present scenes awful enough in all conscience to be worthy of earnest study; but scene after scene is the same. Rags, dirt, filth, wretchedness, the same figures, the same faces, the same old story of one room unfit for habitation yet inhabited by eight or nine people, (...) the same shameful neglect by the owner of the property of all sanitary precautions, rotten floors, oozing walls, broken windows, crazy staircases, tileless roofs, and in and around the dwelling-place of hundreds of honest citizens the nameless abominations which could only be set forth were we contributing to the Lancet instead of writing a book".

17 Para uma apresentação mais detalhada desse gótico político em João do Rio, cf. SASSE, 2016. 
A distopia, assim como o gótico, é uma categoria heterogênea de difícil delimitação, circulante não só na literatura, mas também em outras áreas como a filosofia e a sociologia. Por isso o gênero ${ }^{18}$, em algumas definições mais flexíveis, acaba se tornando sinônimo de uma ficção política gótica. Para autores que enquadram no escopo do gênero obras como $O$ processo (1925), de Franz Kafka, O senhor das moscas (1954), de William Golding, ou mesmo A revolução dos bichos (1945), do próprio Orwell, o elemento definidor da distopia está centrando em uma alegoria política que parte de uma visão de mundo gótica do sistema social e da natureza humana, ressaltando temas como paranoia, vigilância, controle, alienação, poder e loucura.

Optaremos, aqui, no entanto, por uma visão mais restrita do gênero distópico enquanto ficção preditiva negativa (cf. SASSE, 2020), ou seja, centrada em uma extrapolação do presente em direção a um futuro magnificando um recorte de aspectos negativos da sociedade contemporânea de forma verossímil - a partir de certas estruturas narrativas recorrentes. $\mathrm{O}$ fazemos justamente porque acreditamos que, sem essa inversão de sinais no uso do tempo feito pelas ficções preditivas em relação ao gótico, não haveria diferenças significativas entre uma ficção gótica de cunho político e muitas dessas distopias do presente.

Sendo o gótico o tipo de literatura que, talvez, melhor comunique as ansiedades e medos de determinado contexto, o começo do século XX será marcado pela sombra dos regimes totalitários, o que levará, entre outros, ao distópico mundo de 1984: uma figura de poder difusa, nunca de fato alcançável; a constante vigilância e a crescente paranoia; a geografia urbana decadente; os excessos de emoção - do minuto do ódio à paixão arriscada; os labirintos do Ministério do Amor; os horrores da tortura.

Ainda que - ou justamente por que - a distopia orwelliana seja um exemplo perfeito do uso desse gótico político na representação monstruosa de um sistema social, é antecedido por exemplos pouco explorados fora dos círculos mais especializados da crítica da ficção distópica. Nos referimos às distopias anticapitalistas que começam a tomar forma em finais do século XIX e começos do XX, funcionando como gêmeos sombrios das utopias socialistas como Looking Backward (1888), de Edward Bellamy - nos esforços de conscientização social. Dentre elas, gostaríamos de ressaltar O tacão de ferro (1908), de Jack London.

London é um autor ideal para exemplificar a trajetória desse uso político do gótico nas representações sombrias da capital inglesa em direção aos pesadelos do futuro. $\mathrm{O}$ autor, que

18 Trabalharemos com o termo gênero aqui nos dois casos, mas tendo em mente que tanto a distopia quanto o gótico, em parte justamente por essa aplicação ampla, são vistos, muitas vezes como categorias mais abrangentes, como poéticas, modos narrativos, arquigêneros etc. No entanto, tal discussão não cabe ao presente trabalho, havendo sido nossa opção manter a mais tradicional denominação de gênero. 
em $O$ tacão de ferro apresentará a ascensão de uma tirânica oligarquia nos EUA, o sofrimento dos cada vez mais miseráveis e a luta de resistência dos opositores socialistas, já flertava com o gótico político antes da produção de sua primeira distopia: em 1902, London decide se mudar para East End, uma das áreas mais miseráveis de Londres, a fim de produzir uma espécie de reportagem de campo sobre a vida entre os mais pobres na mais opulenta metrópole do planeta.

O resultado é um livro que mistura narrativa, entrevistas com os moradores, dados estatísticos e discurso político, em que vemos uma profunda marca da representação gótica do espaço e de seus moradores - em alguns pontos bem semelhante ao que veremos João do Rio fazer, aqui, em algumas de suas crônicas, como "Visões d’Ópio" ou "Sono calmo". London dá sequência, assim, à tradição de Godwin, Dickens e Reynolds de utilizar o gótico a fim de intensificar sua retórica da injustiça social, como o próprio título do livro já dá indica: The People of the Abyss (1903).

London bebe dessa experiência em East End para imaginar uma situação que magnificaria a desigualdade do sistema capitalista para níveis extremos através de uma distopia projetada em um futuro próximo. Nela, “[o] capitalismo, apodrecendo de maduro, produziu um monstruoso desdobramento, a oligarquia" (LONDON, 2011, p. 15). Os donos dos meios de produção, cansados de uma manipulação política indireta e trabalhosa, assumem o protagonismo político, tomam o poder militar e caçam e exterminam seus dissidentes. Assim como em 1984, estão presentes os temas de vigilância, controle e poder nas mãos de um sistema tirano. Há, porém, em London, uma preocupação pela representação dessa camada mais pobre, que na obra de Orwell só é vista de relance.

Através das descrições que encontraremos das moradias e condições dos miseráveis que compõem a camada mais baixa da sociedade apresentada em $O$ tacão de ferro, já é possível ver a semelhança com as representação das partes mais pobres da Londres de The People of the Abyss. No entanto, London dá sinais explícitos da base para a construção dessas cenas ao denominar essa classe degradada com o mesmo título de sua anterior obra:

\footnotetext{
A condição do povo do abismo dava dó. (...) Eles viviam como animais em grandes e esquálidos guetos operários, exasperados em meio à miséria e à degradação. (...) Um verdadeiro exército deles trabalha agora na construção de Ardis, alojado em barracas miseráveis onde a vida familiar não pode existir, e onde a decência é substituída por uma degradante bestialidade. Na verdade, é nos guetos operários que vivem as feras do abismo, feras que os próprios oligarcas criaram, mas cujo rugido eles tanto temem. (LONDON, 2011, p. 227)
}

A comparação dessa classe mais pobre a bestas e feras - recorrente sobretudo na tradição do gótico político oitocentista, em que as recentes teorias de Darwin criam uma 
ansiedade sobre o lado animalesco do homem - aponta diretamente para de The People of the Abyss, em que London descreve, no capítulo "A vision of the night", o que ele denomina "um zoológico de bípedes vestidos que mais pareciam bestas que humanos", olhando "de forma incisiva e faminta, como lobos da sarjeta". Mesmo nessa visão ainda realista das classes mais baixas, London já os descreve como "uma nova espécie, uma raça de selvagens urbanos"19 (LONDON, 1903, p. 284-5).

Assim como em The People of the Abyss e em autores anteriores dessas tradição, a caracterização dos miseráveis parece buscar, ao mesmo tempo, terror e piedade por parte do público, muitas vezes desumanizando por completo essa parte da população. Ainda que sejam obras claramente guiadas por um ideal socialista simpático aos mais pobres, London representa um estado de reificação tão profundo nessa classe que, indo além da mera metáfora das bestas, os transforma em uma massa monstruosa irracional e faminta, precursora das hordas zumbi do horror no século XX:

\begin{abstract}
Eu já havia visto o povo do abismo antes, havia cruzado seus guetos e parecia conhecê-lo; mas, agora, era como se o visse pela primeira vez. Sua estúpida apatia desaparecera. Era dinâmico agora: um espetáculo de horror. Agitava-se diante de meus olhos uma onda concreta de cólera, rugindo e crescendo, uma turba carnívora embriagada com o uísque saqueado nos armazéns, embriagada de ódio, embriagada pelo desejo de sangue; homens, mulheres e crianças cobertos de trapos, criaturas de bestuntos ferozes, de inteligência turva, em cujos caracteres se havia borrado o que tinham de divino para estampar a figura da besta. Criaturas tísicas e anêmicas, enormes bestas de carga peludas em cujas veias corria o sangue do macaco e do tigre. Rostos lívidos, dos quais o líquido vital tinha sido sugado por uma sociedade de vampiros; formas inchadas pelo sofrimento e pela corrupção do corpo. Tinham a cabeça seca e ostentavam uma barba como a dos patriarcas; era uma juventude corrompida que apodrecia com a idade, cujas faces diabólicas eram torcidas e deformadas; monstros desfigurados pelos estragos das doenças e pelos horrores de uma fome sem fim; dejetos e escórias da vida, hordas enfurecidas, bestas que rugem e que guincham. (LONDON, 2011, p. 242-243)
\end{abstract}

Essa visão dantesca dos miseráveis em revolta auxilia a consolidar o ponto de que, nesse uso político do gótico, personagens, espaço e tempo se confundem na figura de um sistema monstruoso: despersonificada, a massa se torna uma metonímia do contexto de degradação criado pela plutocracia; em seus corpos se inscreve os signos da miséria, ao mesmo tempo esculpindo neles as mazelas da sociedade e desfigurando sua humanidade; em última instância, não se trata mais de um povo, mas da monstruosa face oculta da exploração capitalista.

Se, nessas distopias anticapitalistas da virada do século, avulta-se a desigualdade como um eixo, alinhando-as às visões góticas da cidade oitocentista - que retornam, posteriormente,

19 "a menagerie of garmented bipeds that looked something like humans and more like beasts" / "sharply, hungrily, gutterwolves" / "a new species, a breed of city savages". 
com força nas distopias capitalistas pós-modernas -, outras se aproximarão dos temas de controle e poder do Estado já vistos em Caleb Williams e Tempos difíceis. Ainda que London, através dos discursos sempre sóbrios de seu protagonista em defesa do socialismo contra esse “monstruoso desdobramento", apele à razão para consolidar sua crítica ao sistema, também o fará através dos efeitos estético-retóricos que encontram no maquinário gótico seus mais eficazes resultados.

\section{Considerações finais}

Lidar com dois temas profundamente heterogêneos e cujos embates teóricos são inúmeros e complexos é um desafio do qual esperamos ter saído com um mínimo de coerência. Buscamos, aqui, ter mostrado, ainda que brevemente, como a distopia não apenas lança mão de mecanismos do gótico em sua representação, mas também se incorpora a uma tradição de representação negativa de sistemas sociopolíticos que surge ainda no século XVIII e se perpetua até a contemporaneidade.

Fomos obrigados a deixar de lado, em prol da visão panorâmica, inúmeros estudos de caso que poderiam fortalecer nossos argumentos, tanto no gótico setecentista, em que outros romances dialogam bastante com temas caros à distopia, como The Monk (1796), de Matthew Lewis, quanto no gótico urbano novecentista, sobretudo na tradição criminal das Newgate novels a que muitos filiam Dickens. Na ficção distópica, poderíamos ter, ainda, explorado Caesar's Column (1890), de Ignatius Donnelly, que antecipa em quase vinte anos as temáticas levantadas por London, também carregando de tons góticos a visão de uma plutocracia tirana que oprime violentamente os mais pobres.

Acreditamos, no entanto, que tais reflexões possam colaborar nos diálogos que a crítica da ficção distópica está estabelecendo com uma visão mais recente dos estudos do gótico que passa a encará-lo não mais como um gênero delimitado historicamente, mas como uma poética voltada para a representação disfórica das ansiedades de seu tempo.

\section{REFERÊNCIAS}

BOTTING, Fred. Gothic. Nova Iorque; Londres: Taylor \& Francis, 2005.

DICKENS, Charles. Tempos difíceis. Trad. José Baltazar Pereira Júnior. São Paulo: Boitempo, 2014. 
FRANÇA, Júlio. Introdução. In: Poéticas do mal: a literatura do medo no Brasil (1840-1920). Rio de Janeiro: Bonecker, 2017. pp. 19-35.

GODWIN, William. Adventures of Caleb Williams. Vol. 1. Nova Iorque: J. Harper, 1831. . Adventures of Caleb Williams. Vol. 2. Nova Iorque: J. Harper, $1831 \mathrm{~b}$.

HOGLE, Jerrold E. Introduction: the Gothic in western culture. In: (Ed.). The

Cambridge Companion to Gothic Fiction. Cambridge: Cambridge University Press, 2002.

LONDON, Jack. The People from the Abyss. Londres: Macmillan \& Co., 1903. O tacão de ferro. Trad. Afonso Teixeira Filho. São Paulo: Boitempo, 2011.

PUNTER, David. The Literature of Terror: a history of gothic fictions from 1765 to the present day. Nova Iorque, Oxon: Routledge, 2013.

REYNOLDS, George. The Mysteries of London. Urbana, Illinois: Project Gutenberg, 2014. Disponível em: <http://www.gutenberg.org/files/47312/47312-h/47312-h.htm>. Acesso em: 21 ago 2020.

SADE, Donatien Alphonse François, conde de. Os crimes do amor e A arte de escrever ao gosto do público. Tradução de Magnólia Costa Santos. Porto Alegre: L\&PM, 2002.

SASSE, Pedro. "Monstruosidades na ficção distópica e pós-apocalíptica". In: CARDOSO, André; SASSE, Pedro (Org.). Distopia e monstruosidade. Rio de Janeiro: Dialogarts, 2020. p.172-196.

Terror e crime na literatura brasileira finissecular. 2016. 153 f. Dissertação (Mestrado em Teoria da Literatura e Literatura Comparada), Faculdade de Letras, UERJ, Rio de Janeiro, 2016.

SIMS, George R. How the poor live and Horrible London. Piccadilly: Chatto \& Windus, 1889.

Recebido em 25/9/2020.

Aceito em 18/11/2020. 